\title{
ANÁLISE DAS MANIFESTAÇÕES PATOLÓGICAS PRESENTES NA PONTE SITUADA SOBRE O RIO TOCANTINS EM PORTO NACIONAL-TO
}

\author{
RAMALHO DA SILVA, THAMIRES \\ Bacharel em Engenharia Civil \\ Ceulp/Ulbra \\ Tocantins; Brasil \\ thamiresramalho1@gmail.com
}

\author{
HENRIQUE DE MELO RIBEIRO, FÁBIO \\ Dr. em Ciências do Ambiente \\ Ceulp/Ulbra \\ Tocantins; Brasil \\ fabioribeiro@ceulp.edu.br
}

\section{RESUMO}

O presente trabalho foi desenvolvido na ponte situada sobre o Rio Tocantins, localizada na Rodovia Estadual TO-255, trecho de Porto Nacional - TO. Trata-se de uma ponte construída em 1978, que desde cinco anos após a sua inauguração vem apresentando problemas, que foram agravados devido à ausência de manutenção, comprometendo a sua durabilidade e vida útil, fato este que resultou em sua atual interdição parcial. $\mathrm{O}$ estudo objetivou mapear e diagnosticar as manifestações patológicas em três dos elementos considerados pela NBR 9452 (ABNT, 2016) como principais, sendo eles os caixões e os pilares; e em um elemento considerado por essa mesma norma como complementar, sendo esse as juntas de dilatação. Após as inspeções realizadas, verificou-se que a condição da ponte é crítica, tendo como manifestação patológica de maior incidência a reação àlcali-agregado e corrosão das armaduras, responsáveis majoritariamente pela deterioração dos elementos principais da ponte.

Palavras-chave: manifestações patológicas, inspeção especial, pontes.

\section{ABSTRACT}

The present work was developed on the bridge over the Tocantins River, located on the TO-255 State Highway, part of Porto Nacional - TO. This is a bridge built in 1978, which since five years after its opening has been presenting problems, which were aggravated due to the lack of maintenance, compromising its durability and useful life, a fact that resulted in your current partial interdiction. The study aimed to map and diagnose the pathological manifestations in three of the elements considered by NBR 9452 (ABNT, 2016) as the main ones, namely the coffins, the pillars and the stringers; and in an element considered by that same standard as complementary, which is the expansion joints. After the inspections, it was verified that the bridge condition is critical, having as pathological manifestation of higher incidence the reaction to alkali-aggregate and reinforcement corrosion, mainly responsible for the deterioration of the main elements of the bridge.

Keywords: pathological manifestations, special inspection, bridges.

\section{INTRODUÇÃO}

Segundo Lemos (2005) no Brasil ainda não há uma cultura de manutenção das obras de arte especiais. Ocorre que após concluídas essas estruturas são desassistidas, resultando no crescente grau de deterioração com passar do tempo. Apenas quando apresentam um alto grau de comprometimento essas são recuperadas, resultando em um custo mais elevado, se comparado com as medidas de manutenção preventiva que poderiam ser realizadas.

Nesse contexto, sobre o Rio Tocantins, existe uma ponte com 900 metros de extensão, localizada no município de Porto Nacional, Rodovia Estadual TO - 255, que também apresenta manifestações patológicas agravadas pela carência de manutenção. A mesma consiste em um elo entre a região central do estado com os principais modais de escoamento da produção, como BR-153 e Ferrovia Note-Sul, sendo, portanto, largamente utilizada.

Atualmente este objeto encontra-se com tráfego limitado, sendo liberado apenas para pedestres, bicicletas, motocicletas e carros pequenos, até a publicação deste. Em sua estrutura foi colocado um pórtico de 2,2 metros para impedir o tráfego de veículos pesados, tais veículos tem utilizado a balsa como meio de travessia. 
A postergação das atividades de manutenção resultou no agravamento das manifestações patológicas presentes e por consequência o aumento dos custo de recupeção dessa estrutura. É válido ressaltar que problemas estruturais comprometem a segurança dos usuários, aumentando o risco de acidentes e possíveis danos materiais e/ou humanos.

Em função do exposto, esse estudo visou mapear e diagnosticar as manifestações patológicas presentes na ponte sobre o Rio Tocantins, explicitando as origens, mecanismos e causas para suas ocorrências.

\section{METODOLOGIA}

\subsection{Objeto de estudo}

O objeto estudado está situado na Rodovia Estadual TO-255, trecho de Porto Nacional. Trata-se de uma obra de arte especial (Figura 1) construída em 1978, que possui 8 vãos de 97,8 metros e 2 vãos de 58,80 metros, resultando em 900 metros de comprimento. A ponte é constituída por 10 trechos, que são apoiados em 9 pilares e 2 encontros, sendo que os 8 trechos intermediários são formados por vigas isistáticas de 40 metros de comprimento, que são apoiadas em balanços de 28,9 metros de comprimento dos 9 pilares intermediários. No meio da ponte, onde os pilares alcançam a maior altura de 32 metros, a altura do caixão do balanço é de 5,51 metros (LSE, 2017).

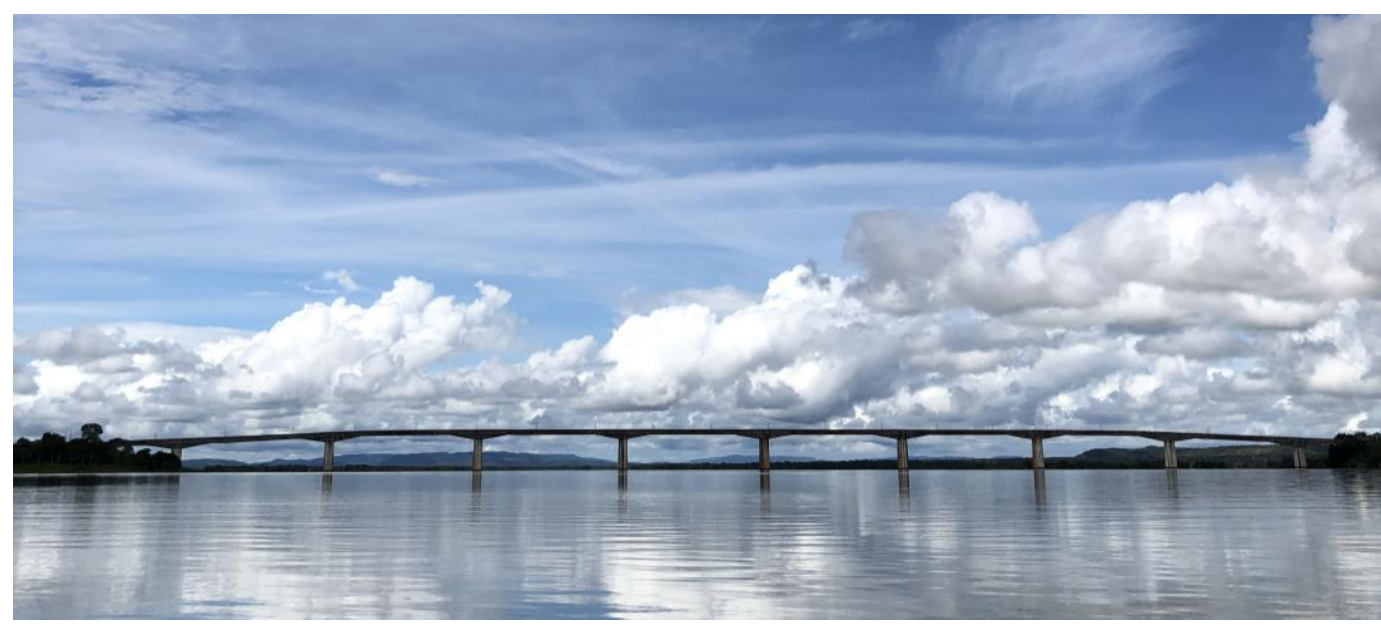

Figura 1: Objeto de estudo

\subsection{Inspeções}

Optou-se por delimitar os elementos que seriam inspecionados. Os procedimentos foram desenvolvidos em três dos elementos considerados pela NBR 9452 (ABNT, 2016) como principais, devido ao dano em tais ser capaz de levar ao colapso parcial ou total da obra, sendo eles os caixões (tabuleiro e vigas), pilares e longarinas; e em um elementos considerado por essa mesma norma como elementos complementar, cujo dano não causa algum comprometimento estrutural, somente funcional e de durabilidade, sendo as juntas de dilatação.

Nos caixões a inspeção foi realizada a partir dos acessos abertos na laje superior. Tratavam-se de 35 janelas para inspeção, que tiveram amostra reduzida para o desenvolvimento desse trabalho. Para tal, considerou-se $95 \%$ de confiança para o cálculo do tamanho da amostra, dado este que segundo Pedrotti (2018) significa que os intervalos de confiança constituídos a partir das amostras de mesmo tamanho, 95\% deles contêm o verdadeiro parâmetro. Foi considerado que a vistoria seria realizada em $20 \%$ dos caixões, resultando em 7 caixões a serem inspecionados aleatoriamente. Este tamanho amostral resultou em uma margem de erro 34\%. Todos os 9 pilares e as 8 longarinas foram inspecionados.

Foi adotada a metodologia da inspeção especial, descrita na NBR 9452 (ABNT, 2016). Tal inspeção consistiu na análise visual dos elementos e realização de um levantamento fotográfico extenso, com o auxílio da câmera fotográfica Panasonic Lumix DMCFZ47. Para o acesso aos caixões foi utilizada uma escada extensível de 3 metros de altura, e para o acesso aos pilares foi utilizado o barco modelo Pr 600 Sport Motor Mercury 15 Hp. As vigas longarinas não foram inspecionadas proximamente, devido à dificuldade de acesso, porém as suas manifestações patológicas foram mapeadas de acordo com os danos que foram possíveis observar visualmente. 
A fim de caracterizar qualitativamente a manifestação patológica de corrosão das armaduras, realizou-se a asperção de fenolftaleina nos locais em que observou-se tal manifestação, com o intuito de avaliar o mesmo está carbonatado, através do ensaio de verificação do pH. Tal médodo foi executado conforme prescrito pelo CPC-18 (RILEM, 1988).

Dessa forma, durante a inspeção especial foi feita a anotação de todos os sintomas visuais, visando comprovar se os sintomas e a natureza do problema são iguais em todos os elementos ou se existe mais de uma problemática na estrutura. Para que houvesse uma melhor visualização dos dados extraídos, foram elaborados croquis com o mapeamento geral das manifestações patológicas nos elementos.

\section{RESULTADOS E DISCUSSÕES}

Para a análise dos dados extraídos e melhor discussão dos seus resultados, adotou-se a nomenclatura dos elementos da estrutura iniciando a contagem da margem de Porto Nacional à margem de Fátima. Dessa forma, o primeiro pilar situado à margem de Porto Nacional foi nomeado de Pilar 1 (P1) e assim sucessivamente até o Pilar 9 (P9); o mesmo fez-se com as longarinas, denominadas Longarina 1 a Longarina 8; e caixões, seguindo a formatação Caixão PXLYN, onde " $X$ " é o número do pilar correspondente ao balanço inspecionado, "Y" o lado do passeio onde a janela de inspeção está situada, sendo esquerda (E) ou direita (D) e "N" é a margem correspondente (Porto Nacional-1 e Fátima-2). Tais nomenclaturas foram embasadas nos critérios adotados pelo Laboratório de Sistemas Estruturais (LSE) durante as inspeções realizadas, a fim de melhor transcorrer o processo de análise e comparação dos resultados obtidos.

\subsection{Mapeamento das manifestações patológicas}

Notou-se que nas lajes inferiores do tabuleiro (Figura 2) há recorrentes fissuras padrões; em algumas delas foram realizadas injeções de reparo, porém insufisientes, visto que as mesmas vieram a fissurar novamente. Somado a isso, foi constatada a presença de manchas de corrosão e infiltração localizada, além de eflorescências situadas no sentido da fissuração.

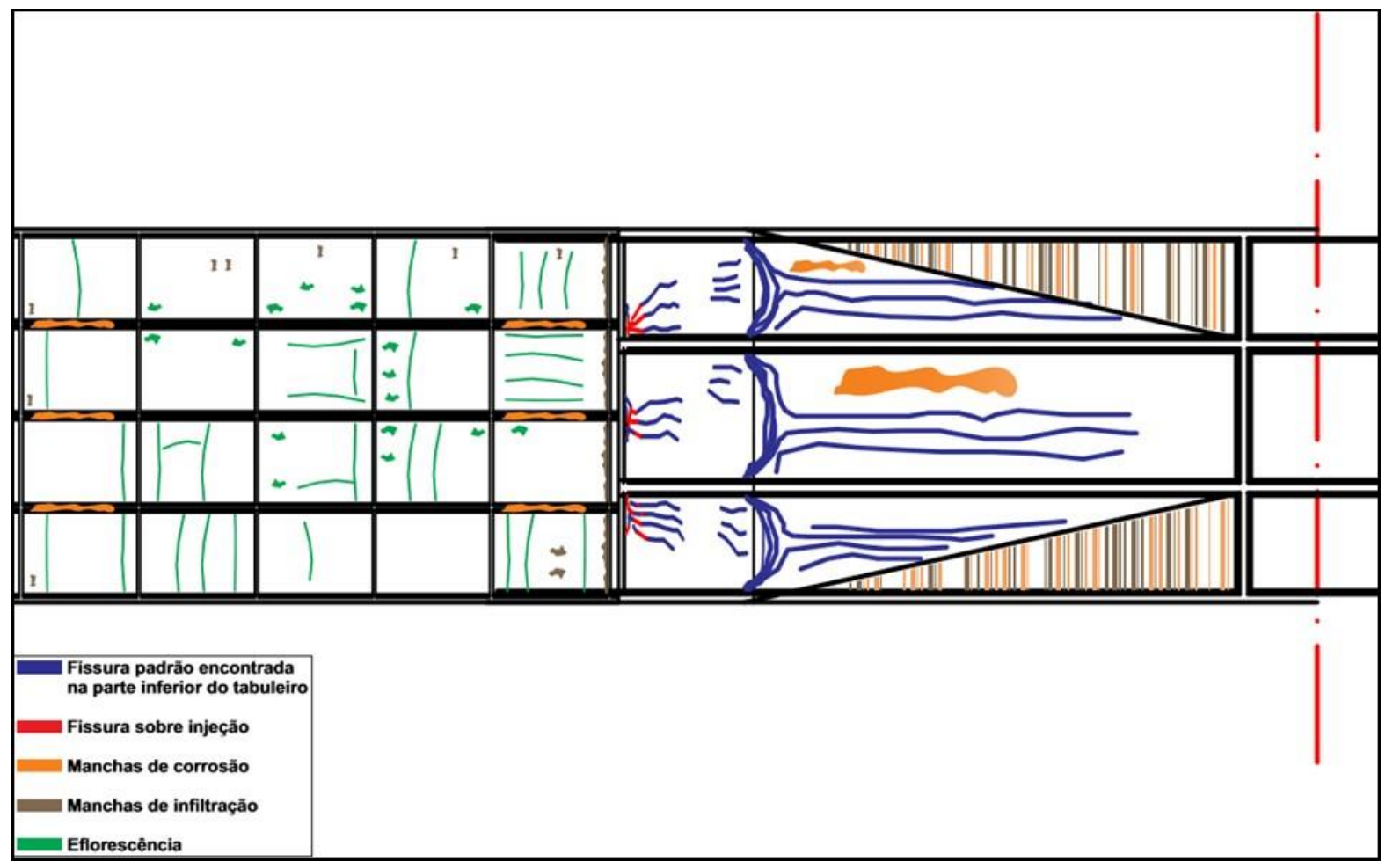

Figura 2: Mapeamento das manifestações patológicas na face inferior do tabuleiro

Nos pilares (Figura 3) foram identificadas a ocorrência de fissuras acentuadas características da reação álcali-agregado (RAA), próximas ao nível d'agua, além de bolor, limo e erosão nesse mesmo local. Ao longo do pilar foi constada a presença corrosão das armaduras, manchas de infiltração e fissuras, sendo que nas fissuras localizadas nas extremidades foram realizados reparos, porém o mesmo foi ineficaz, uma vez que o material se encontra com fissuras e 
desplacamento. Nas extremidades dos pilares também foi verificada a incidência de impacto de embarcações e reparo inadequado.

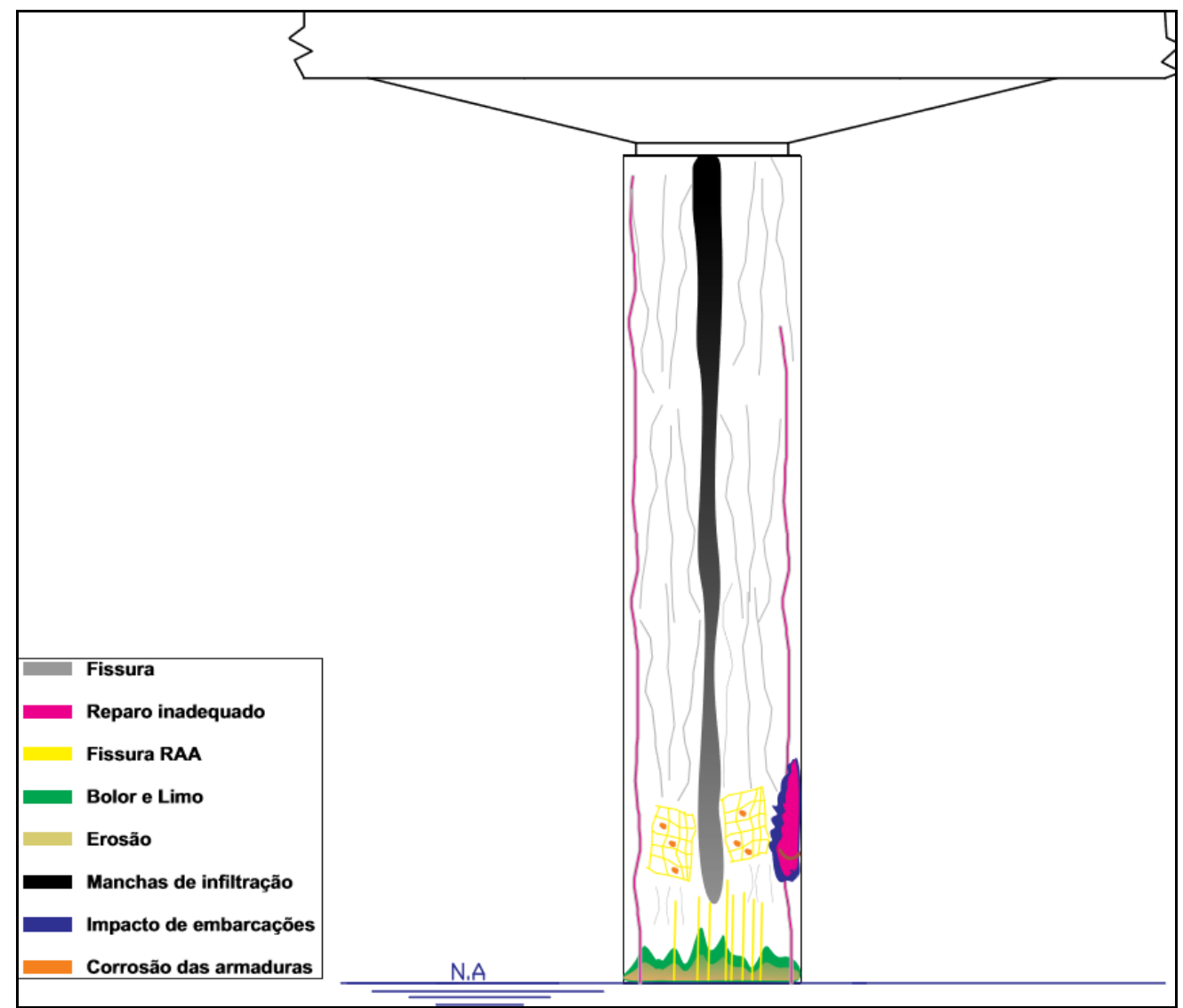

Figura 3: Mapeamento das manifestações patológicas nos pilares

Os caixões (Figura 4) encontram-se com elevada manifestação de fissuras com disposições variadas; nessas há reparos inadequados e surgimento de eflorescências alinhadas às aberturas. No topo dos caixões foram encontrados repetidos pontos de eflorescência com corrosão das armaduras; e fissuras características da RAA.

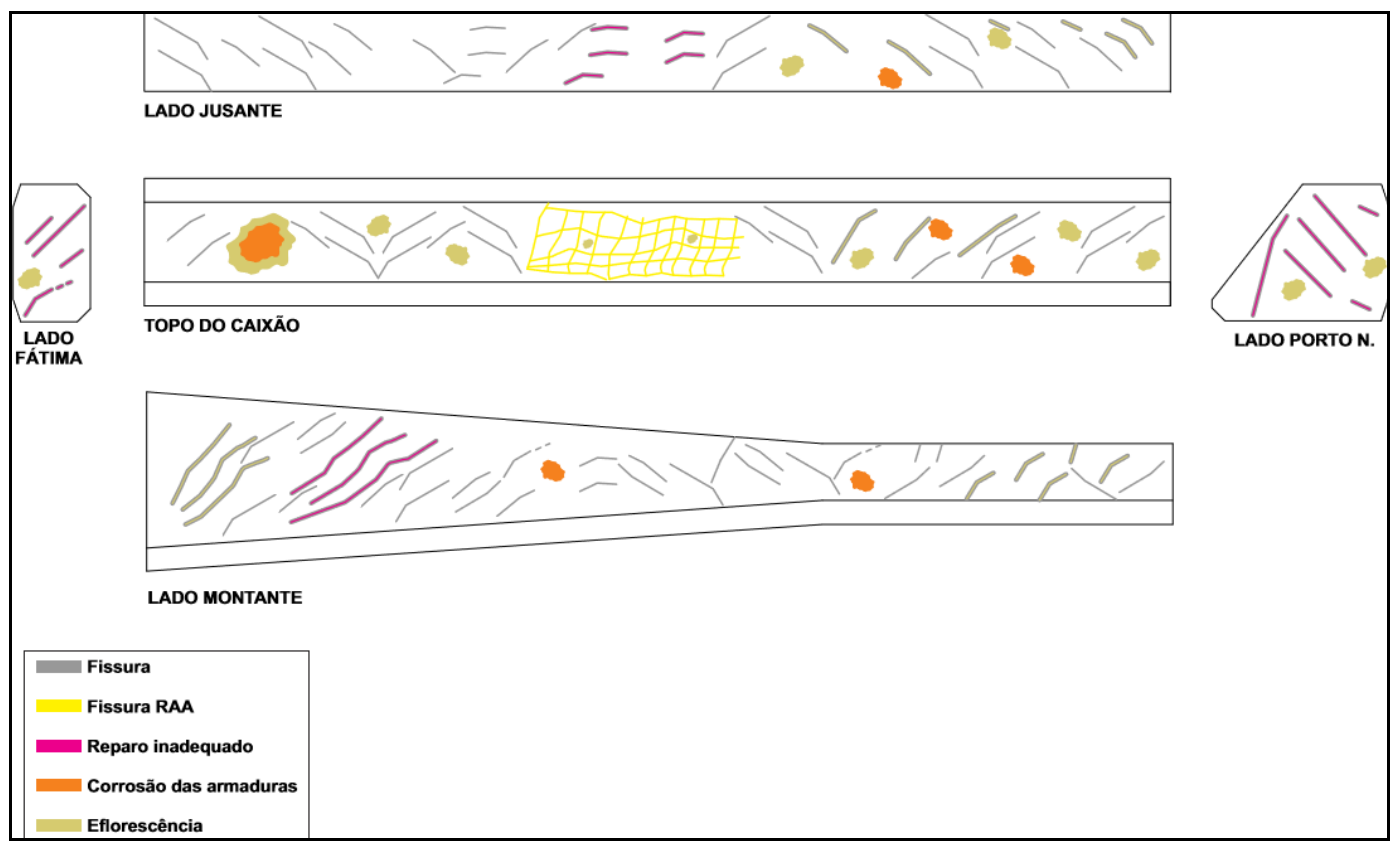

Figura 4: Mapeamento das manifestações patológicas nos caixões 


\subsection{Manifestações Patológicas}

\subsubsection{Corrosão}

Foram constatados pontos de corrosão das armaduras nos pilares e nos caixões (Figura 5). Dentre os nove pilares inspecionados, oito apresentaram armaduras expostas à corrosão, sendo o P9 a exceção; dos sete caixões vistoriados todos apresentaram a referida manifestação patológica.

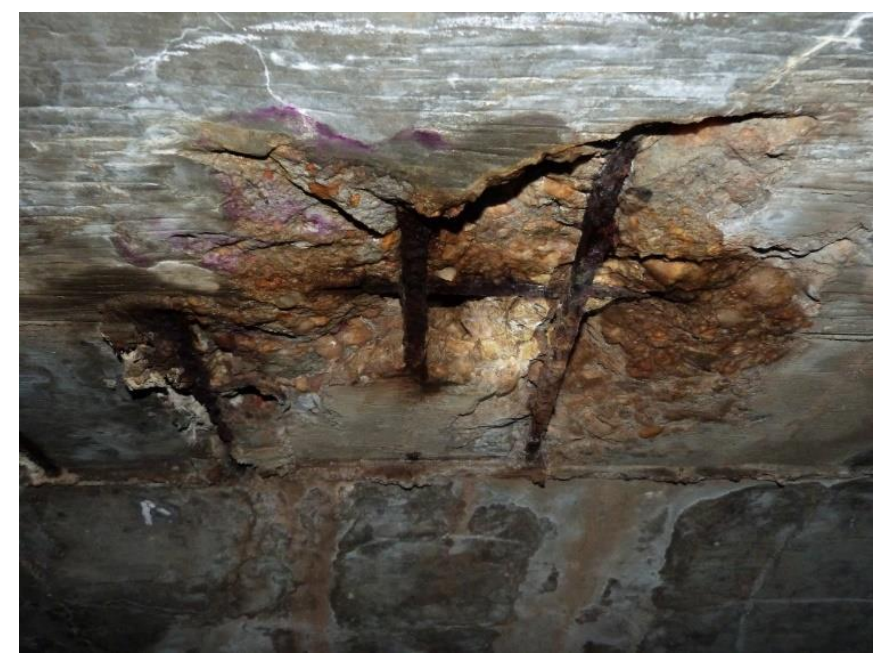

Figura 5: Corrosão das armaduras, Caixão P9LD1

O aspecto visual, acrescido da caracterização do ambiente e aspersão da fenolftaleína nos pontos de armadura exposta, possibilitou a identificação qualitativa da carbonatação do concreto e determinação do ataque às armaduras. Trata-se de uma corrosão eletroquímica generalizada por carbonatação. A corrosão originou-se devido a múltipas causas, dentre elas: cobrimento inadequado, concreto muito poroso, fissuras em decorrência de outras manifestações patológicas e infiltração.

Visualmente, foi possível observar que o concreto é poroso (Figura 6). Conforme Araújo et al. (2014) as bolhas de ar podem amplificar a permeabilidade do concreto, favorecendo a penetração de agentes agressivos. Além disso, as bolhas também podem afetar a formação das camadas protetivas da armadura. A ocorrência de fissuração devido a outras manifestações patológicas propicia o ataque às armaduras, devido a facilidade da passagem dos agentes agressivos. Ademais, amplificam a ocorrência de infiltração, oriunda da insuficiência do sistema de drenagem, acelerando o processo de corrosão.

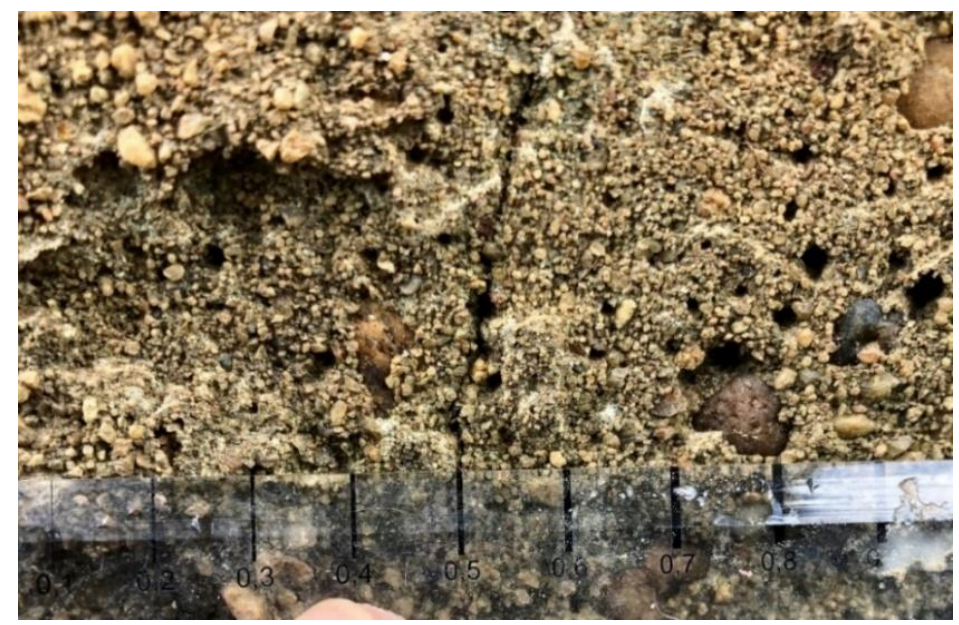

Figura 6: Porosidade do concreto, P1

Verificou-se que o cobrimento não foi executado de acordo com a especificação vigente na época de projeto, visto que de acordo com a NB-1 (ABNT, 1960) o cobrimento necessário para os pilares era de 20mm. Ao verificar as medias de 
cobrimento com o auxílio de um paquímetro analógico, notou-se que apenas o P7 apresenta cobrimento aceitável perante a norma vigente no período da construção e diante a norma válida atualmente, sendo que essa última trata-se da NBR 6118 (ABNT, 2014), onde a mesma dispõe que para obras de CAA I, construídas em concreto armado, o cobrimento nominal dos pilares deve ser de $25 \mathrm{~mm}$. Este fator possui relação direta com o agravamento da corrosão das armaduras nos pilares, pois o mesmo é considerado como uma camada protetora dessas para garantir a vida útil da estrutura.

O Comitê Eurointernacional du Beton (CEB, 2006), em seu boletim de número 162, estabelece níveis de deterioração para elementos de concreto armado sujeitos à corrosão das armaduras, em função de parâmetros observados nos componentes estruturais, como: mudança de cor, lascamento, perda de seção do aço e flechas. Levando em consideração tais critérios e o elevado nível de deterioração nos caixões devido a presença de armaduras rompidas (Figura 7) em todas as seções inspecionadas, que comprometem a vida útil da estrutura e a segurança daqueles que a utilizam, os caixões possuem o nível de deretioração mais agravante da referida classificação, sendo este o nível E.

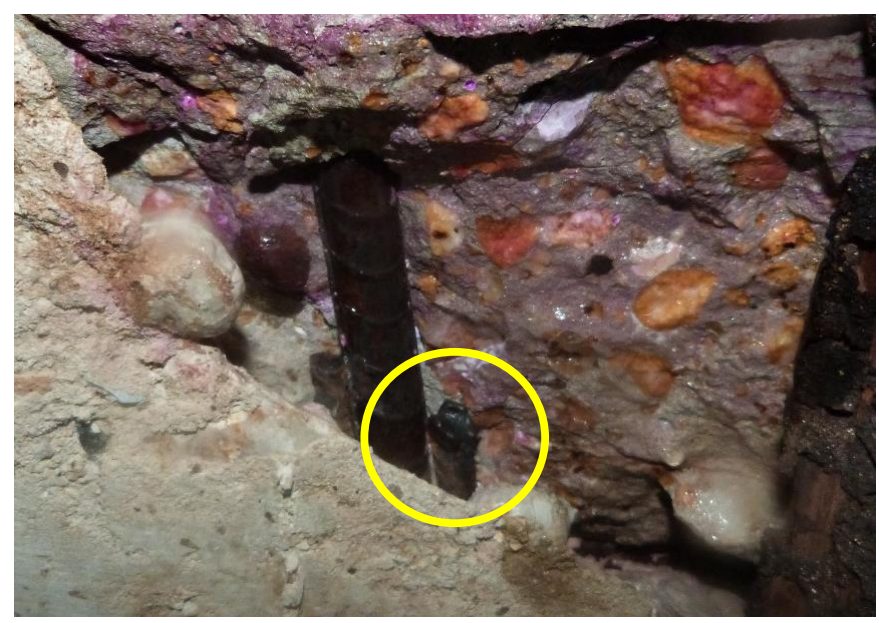

Figura 7: Armadura rompida, Caixão P7LD1

\subsubsection{Lixiviação e Eflorescência}

Durante a inspeção foi identificada a ocorrência de lixiviação em todos os acessos dos caixões vistoriados (Figura 8) e nas longarinas. Tal manifestação patológica possui origem química e mecanismo químico; a mesma ocorre no interior do concreto, não sendo possível a visualização do processo.

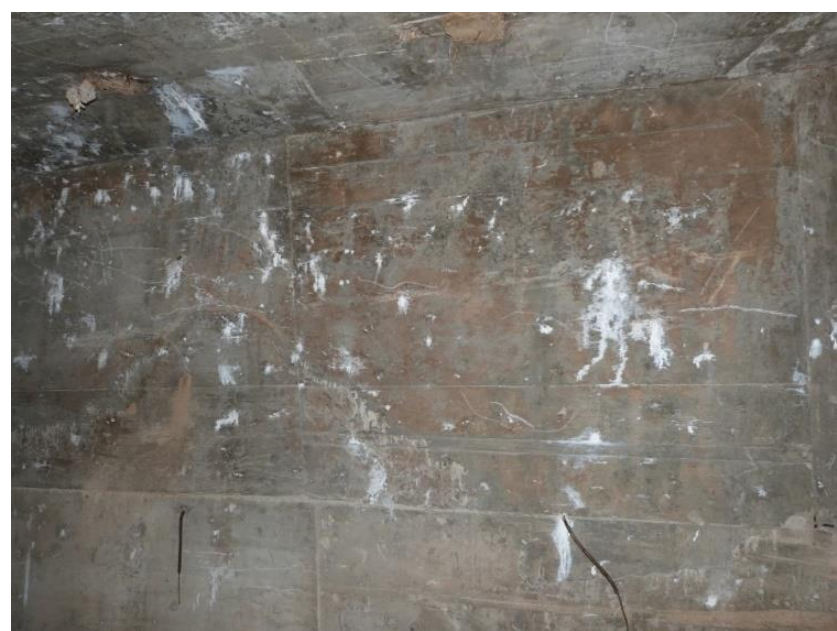

Figura 8: Lixiviação e eflorescência nos caixões

Visto que para a lixiviação do concreto acontecer é necessário a presença de água pura (água da chuva), a manifestação adveio das deficiências que facultam a entrada da água no concreto. Sua causa está ligada a apresentação de fissuras consequentes de outras patologias, como a fissuração presente no pavimento, fissuras em decorrência da RAA, fissuras 
com disposições distintas em todas as faces dos caixões e nas longarinas, e aberturas das juntas de dilatação, que favorecem a passagem da água para o interior desses elementos. Além disso, a insuficiência do sistema de drenagem é responsável pela concentração da água nesse local, uma vez que se este fosse eficaz a água não seria acumulada. Somado a isso, a porosidade do concreto o torna mais propício tal acúmulo.

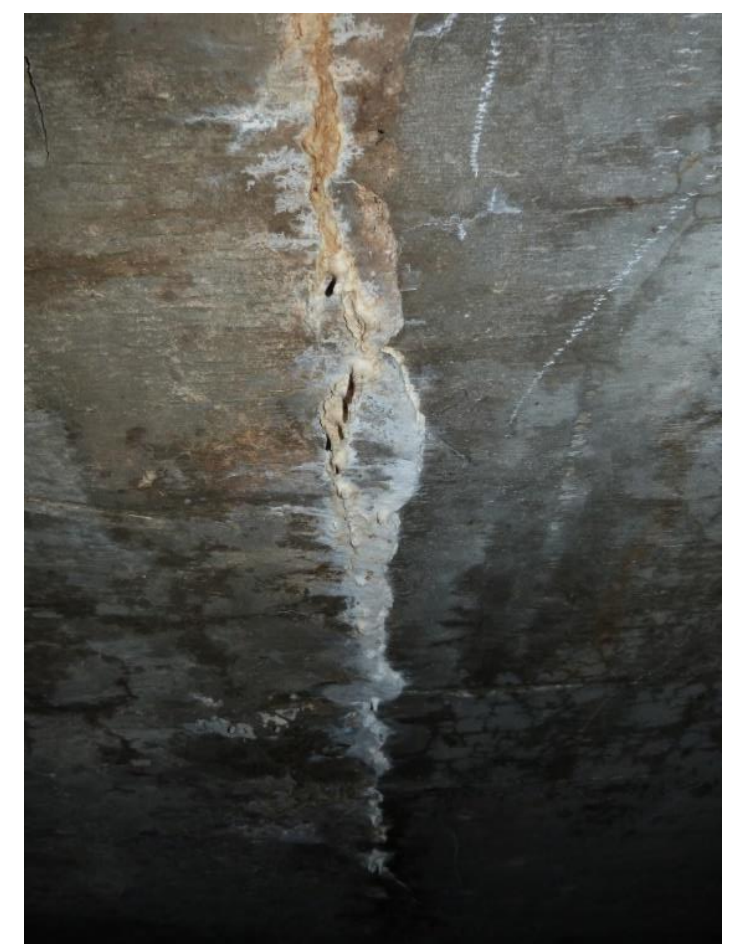

Figura 9: Eflorescência acentuada devido a abertura da junta de dilatação da pista

\subsubsection{Reação Álcali-Agregado}

A RAA trata-se de uma manifestação patológica de origem química e mecanismo químico; a mesma foi identificada nos pilares e interior dos caixões. Ao realizar a inspeção nos pilares notou-se a presença de fissuras espessas (Figura 10), acentuadas próximas ao nível d'água e orientadas em direção à armadura, além de fissuras mapeada (Figura 11) ao longo dos pilares.

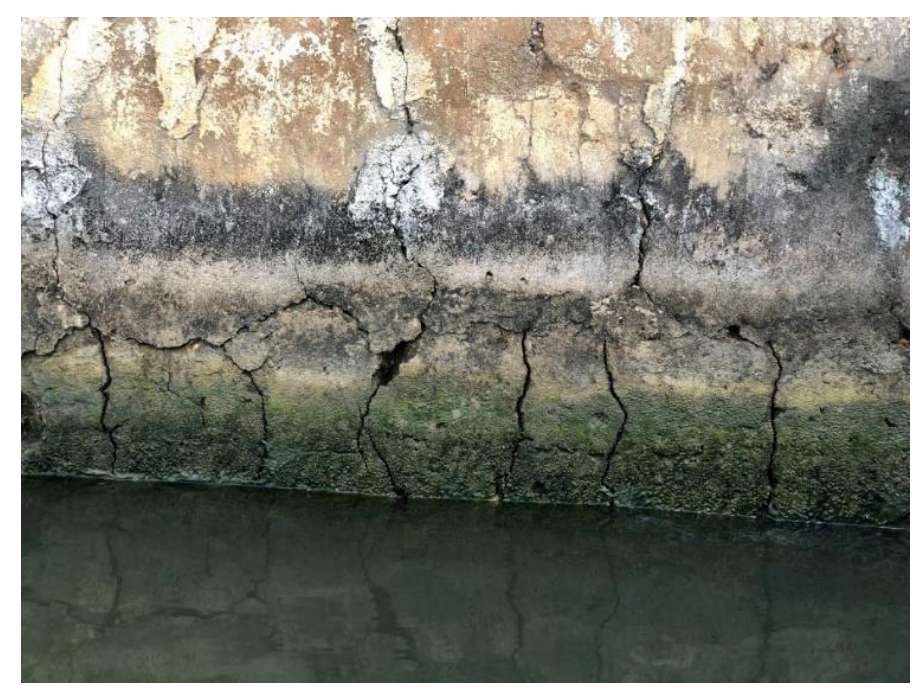

Figura 10: Fissuras espessas devido a RAA 


\section{СВРАT 2020 \\ CONGRESSO BRASILEIRO DE PATOLOGIA DAS CONSTRUÇÕES \\ DE 15 A 17 DE ABRIL | FORTALEZA - CE}

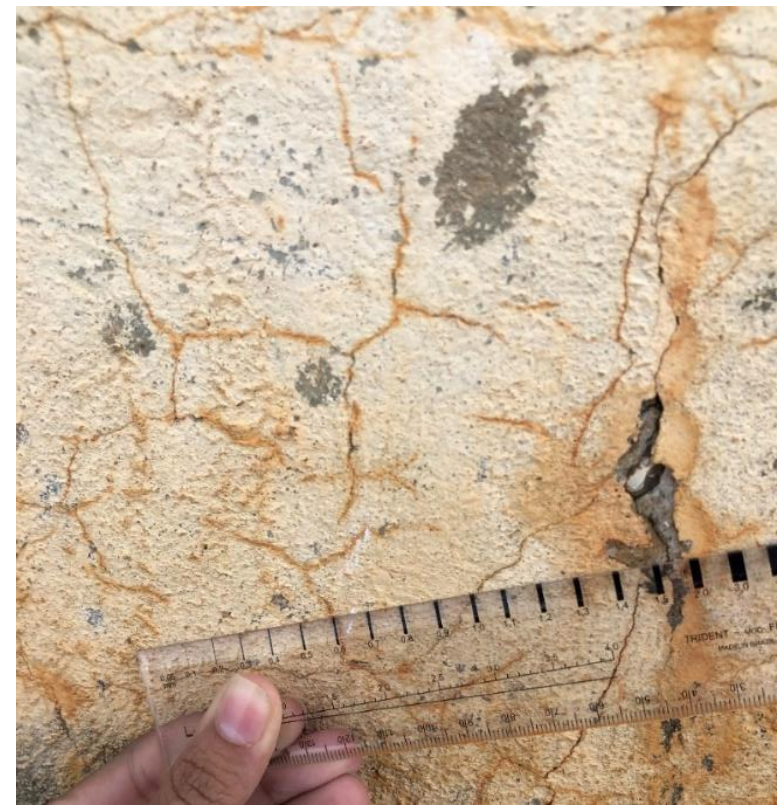

Figura 11: Fissuras mapeadas devido a RAA

Notou-se que as fissuras recorrentes em todos os pilares excedem o limite aceitável da NBR 6118 (ABNT, 2014), que preconiza abertura máxima de $0,4 \mathrm{~mm}$ para CAA I. Essa determinação é dada a fim de garantir a durabilidade da estrutura, visando a proteção adequada das armaduras quanto à corrosão. Logo, a excessiva abertura compromete a durabilidade esses elementos.

No interior dos caixões (Figura 12) a reação foi identificada através da fissuração mapeada característica.

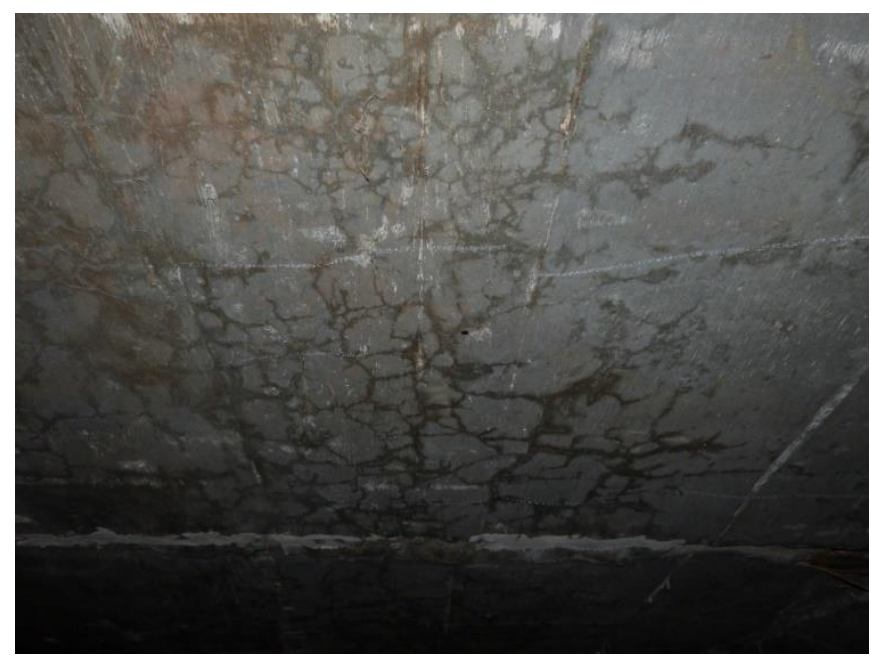

Figura 12: Fissuras mapeadas na face superior dos caixões, Caixão P6LD2

Para que a reação expansiva da RAA aconteça é necessário a presença de minerais reativos, álcalis e água; condicionantes presentes na estrutura, visto que foi utilizado seixo rolado (mineral reativo) como agregado, há presença de sódio e potássio (álcalis) no cimento e a estrutura encontra-se em contato constante com a água. Nesse cenário ocorre a reação expansiva, resultando na formação de um gel (Figura 13) devido a absorção da água, que por sua vez induz o concreto a tensões de tração superiores à sua capacidade. 


\section{СВРАT 2020 \\ CONGRESSO BRASILEIRO DE PATOLOGIA DAS CONSTRUÇÕES \\ DE 15 A 17 DE ABRIL | FORTALEZA - CE}

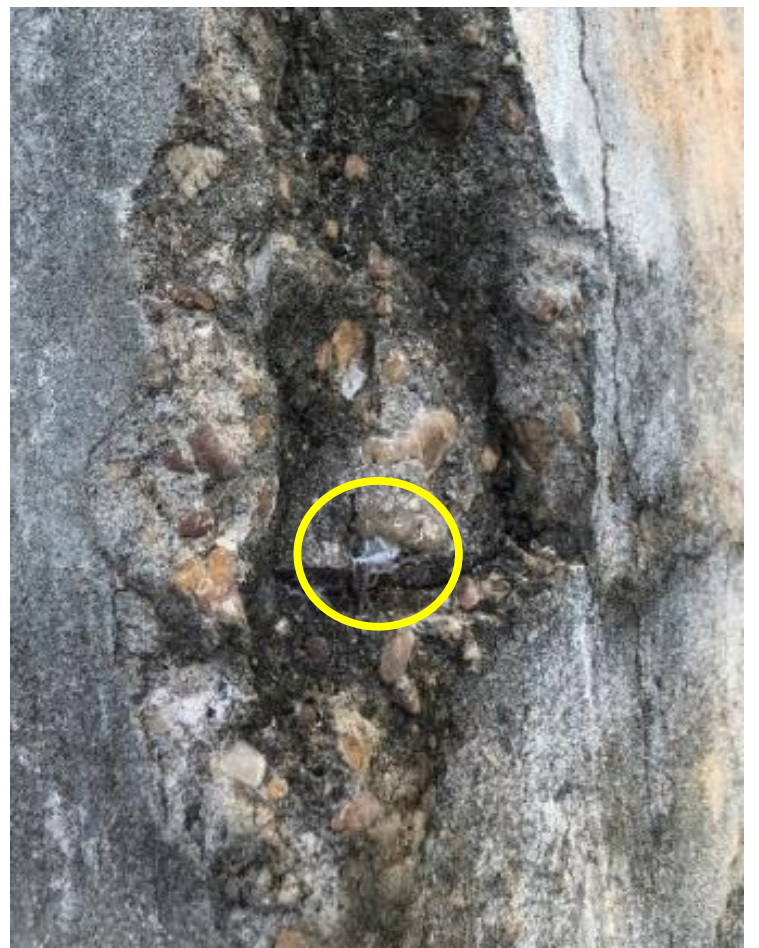

Figura 13: Gel proveniente da RAA ao redor da armadura

\subsubsection{Deterioração nas Juntas de Dilatação}

Observou-se que as juntas de dilatação (Figura 14) se encontram deterioradas, apresentando aberturas excessivas, acúmulo de detritos, desgaste do material de apoio e do material de preenchimento.

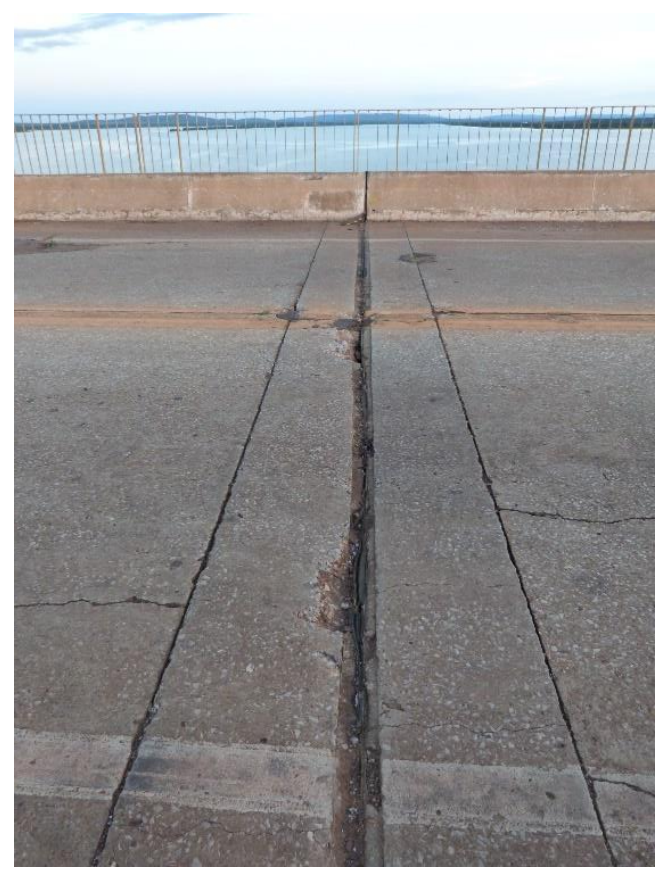

Figura 14: Junta de dilatação desgastada

Possivelmente a apresentação dessas aberturas ocorreram devido a alteração da característica dos veículos que trafegavam sobre a ponte. Entretanto, primordialmente é válido ressaltar que se fossem realizadas manutenções em tais elementos o seu desempenho não seria comprometido. A ausência de manutenção possibilitou a passagem de agentes agressivos pelas aberturas geradas, o que acarretou no surgimento e/ou aceleração de outras manifestações patológicas na OAE, como: lixiviação, eflorescência e corrosão das armaduras. Além de causar desconforto àqueles que trafegam 
sobre a ponte, a abertura das juntas atenua o impacto causados pelos veículos, aumentando a solicitação das cargas na estrutura.

Os apoios das vigas intermediárias são em dente Gerber (Figura 15), com aparelhos de apoio de Neoprene fretados. Os mesmos estão situados nos encontros das juntas e apresentam deterioração visível. O processo de infiltração d'água também aceleram o processo corrosivo nos dentes e danificam os aparelhos de apoio.

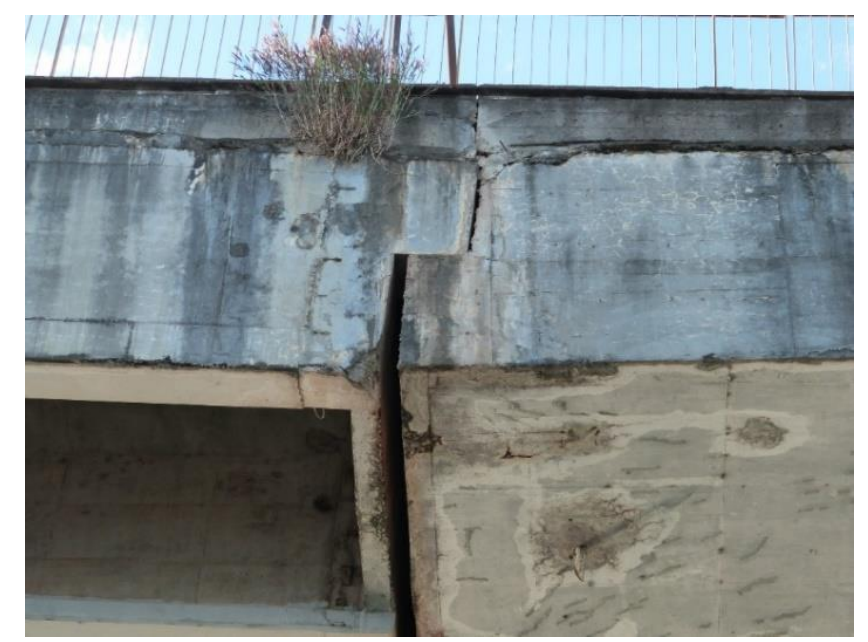

Figura 15: Gerber situado entre os pilares P1 e P2

\subsubsection{Fissuras}

Foram identificadas fissuras no interior dos caixões (Figura 16), com tipologias distintas das características à RAA. A fim de levantar a possível causas para o seu surgimento, realizou-se pesquisas bibliográficas para comparar as características dessas com as apresentadas na literatura.

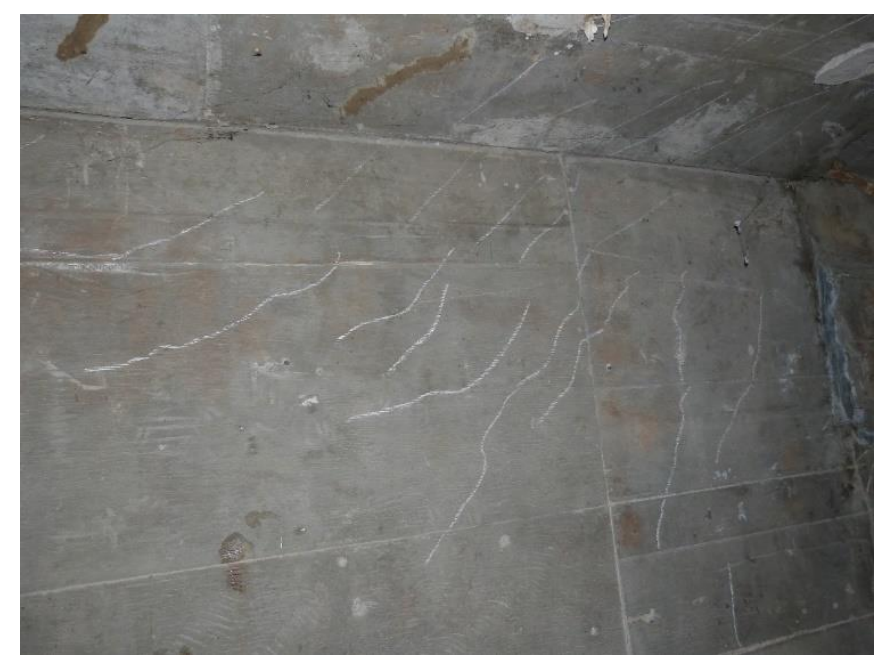

Figura 16: Fissuras inclinadas no interior dos caixões

Possivelmente as fissuras são advindas de cisalhamento. Bastos (2017) diz que a ruptura por efeito de força cortante é iniciada após o surgimento de fissuras inclinadas, causadas pela combinação de força cortante, momento fletor e eventualmente forças axiais. A quantidade de variáveis que influenciam na ruptura é muito grande, como geometria, dimensões da viga, resistência do concreto, quantidade de armaduras longitudinal e transversal, características do carregamento, vão, etc. A Figura 17 ilustra como tal fissura é manifestada nas vigas, de forma semelhante às apresentadas nos caixões. 

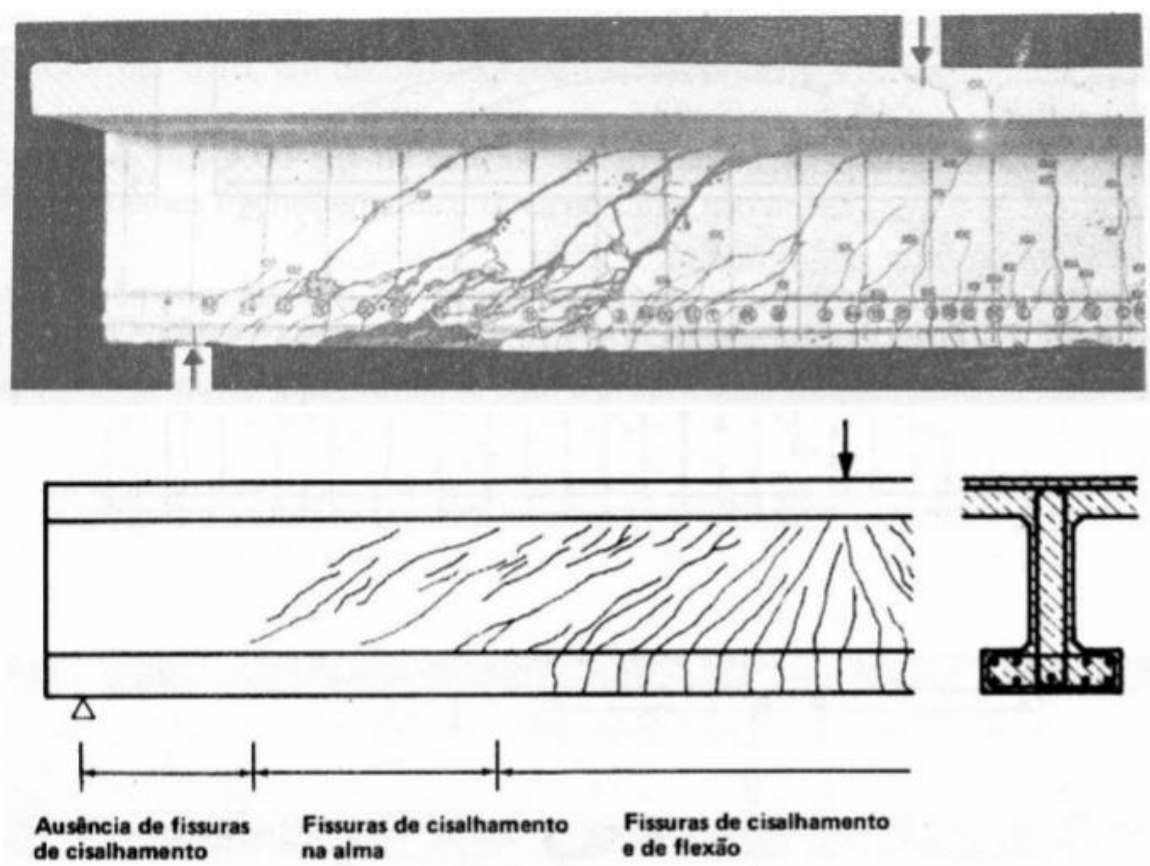

Ausencia de fissuras
de cisalhamento na alma

- de flexäo

Figura 17: Fissuras por cisalhamento em vigas (Fonte: Bastos, 2017)

Notou-se que em todos os caixões vistoriados há fissuras com aberturas superiores a $0,4 \mathrm{~mm}$, limite aceitável para classe de agressividade ambiental 1. Portanto, comprova-se que tais fissuras tem relação direta com o comprometimento da durabilidade da estrutura, conforme explicito na NBR 6118 (ABNT, 2014).

\subsubsection{Erosão}

Observou-se a presença de erosão nos pilares (Figura 18), especialmente nos locais próximos ao nível d'água. Tal ocorrência refere-se a uma manifestação patológica de origem física e mecanismo físico, onde o desgaste da superfície do concreto é dado pela ação abrasiva de fluidos contendo partículas sólidas em suspensão.

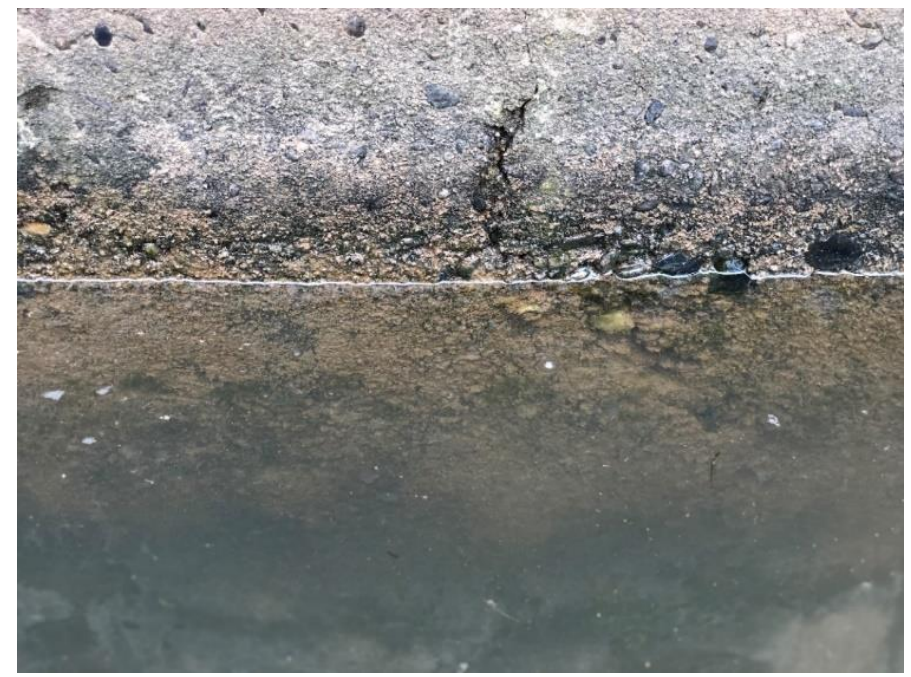

Figura 18: Manifestação de erosão nos pilares, P1

Notou-se que a causa de tal problemática foi a dosagem inadequada do concreto, com a utilização de seixo rolado como agregado, pois o mesmo não possui resistência aos esforços o qual é submetido. A constância do processo de erosão resultou na exposição do agregado, evoluindo ainda para o surgimento de buracos em alguns, contribuindo para a penetração de agentes agressivos. 
Em 2001 houve o represamento do Rio Tocantins para a formação da Barragem de Lajeado, anteriormente a obra de arte especial era submetida ao nível de água em regime de enchentes e vazantes, entretanto, a partir do represamento, a sua estrutura passou a ser exposta continuamente na cota de 20 metros acima da cota de referência da época da sua construção, assinala o LSE (2017). Dessa maneira, a formação do lago contribuiu para o processo erosivo, que por sua vez ocasionou a sedimentação. A variação do nível d'água nos pilares cooperou para que o desgaste fosse acentuado com o passar dos anos.

\section{CONCLUSÃO}

A análise das manifestações patológicas em obras de artes especiais é relevante devido à importância econômica, técnica e social de tais estruturas, tornando primordial a seguridade do seu desempenho e durabilidade. Através da inspeção realizada nesse estudo foi possível verificar que a referida ponte apresenta manifestações patológicas generalizadas, que tem acarretado problemas estruturais, funcionais e de durabilidade na mesma, de acordo com os parâmetros da NBR 9452 (ABNT, 2016). As principais responsáveis pelo comprometimento dessa são as manifestações da RAA e corrosão das armaduras.

O fato de não haver um cronograma de manutenção da estrutura, tem acarretado em sua deterioração acelerada, colocando em risco a segurança daqueles que a utilizam. Destarte, a atual restrição do tráfego sobre a ponte é necessária, em razão do contínuo agravamento das manifestações patológicas comprometerem a segurança dos usuários.

\section{AGRADECIMENTOS}

Aos amigos que colaboraram durante a realização das inspeções.

\section{REFERÊNCIAS}

ARAUJO, Adriana de et al. Comportamento da armadura em concreto poroso: estudo de caso. Techné, São Paulo, n. 212, p. 44-48, nov 2014.

ASSOCIAÇÃO BRASILEIRA DE NORMAS TÉCNICAS. NB-1: Cálculo e execução de obras em concreto armado. Rio de Janeiro, 1960.

ASSOCIAÇÃO BRASILEIRA DE NORMAS TÉCNICAS. NBR 6118: Projeto de estruturas de concreto Procedimento. Rio de Janeiro, 2014.

ASSOCIAÇÃO BRASILEIRA DE NORMAS TÉCNICAS. NBR 9452: Inspeções de pontes, viadutos e passarelas de concreto - Procedimento. Rio de Janeiro, 2016.

BASTOS, P. S. S. Dimensionamento de vigas de concreto armado à força cortante. Estruturas de Concreto II, p. 1$79,2017$.

CEB-FIP Model Code 2006. Model code for service life design. Lausanne, CEB, Bulletin n. 34, p. 116,2006.

LABORATÓRIO DE SISTEMAS ESTRUTURAIS. Inspeção visual da estrutura da ponte sobre o Rio Tocantins, Porto Nacional - TO. São Paulo, 2017.

LEMOS, K. Brasileiro Q. Manutenção e Reabilitação de Túneis. 2005. 203 f. Dissertação (Mestrado) - Curso de Engenharia Civil, Departamento de Engenharia Civil e Ambiental, Universidade de Brasília, Brasília, Brasil, 2005.

PEDROTTI, L. Giongo. Tamanho de amostra e poder no Software R. 2018. 54 f. TCC (Graduação) - Curso de Estatística, Universidade Federal do Rio Grande do Sul, Porto Alegre, Brasil, 2018.

RILEM RECOMMENDATIONS. CPC-18: Measurement of hardened concrete carbonation depth. Europa, 1988. 